\title{
Hastanede Yatan 3-18 Yaş Arası Çocukların Düşme Riskinin Belirlenmesi
}

\author{
Kübra ÇAMURCU ${ }^{1}$ (i) Gülay MANAV² (iD) Gonca KARAYAĞIZ MUSLU $^{3}$ (D)
}

${ }^{1}$ Sakarya Eğitim ve Araştırma Hastanesi, Sakarya, Türkiye, kubracamurcu@posta.mu.edu.tr (Sorumlu Yazar/ Corresponding Author)

${ }^{2}$ Muğla Sttkı Koçman Üniversitesi, Sağlık Bilimleri Fakültesi, Hemşirelik Bölümü, Muğla, Türkiye, gulaymanav@mu.edu.tr ${ }^{3}$ Muğla Sıtkı Koçman Üniversitesi, Fethiye Sağlık Bilimleri Fakültesi, Hemşirelik Bölümü, Muğla, Türkiye,

goncamuslu@mu.edu.tr

\begin{tabular}{|c|c|}
\hline Makale Bilgileri & Öz \\
\hline $\begin{array}{l}\text { Anahtar Kelimeler: } \\
\text { Düşme riski, } \\
\text { Çocuk, } \\
\text { Hastanede yatan } \\
\text { çocuk, } \\
\text { Pediatri hemşireliği. }\end{array}$ & 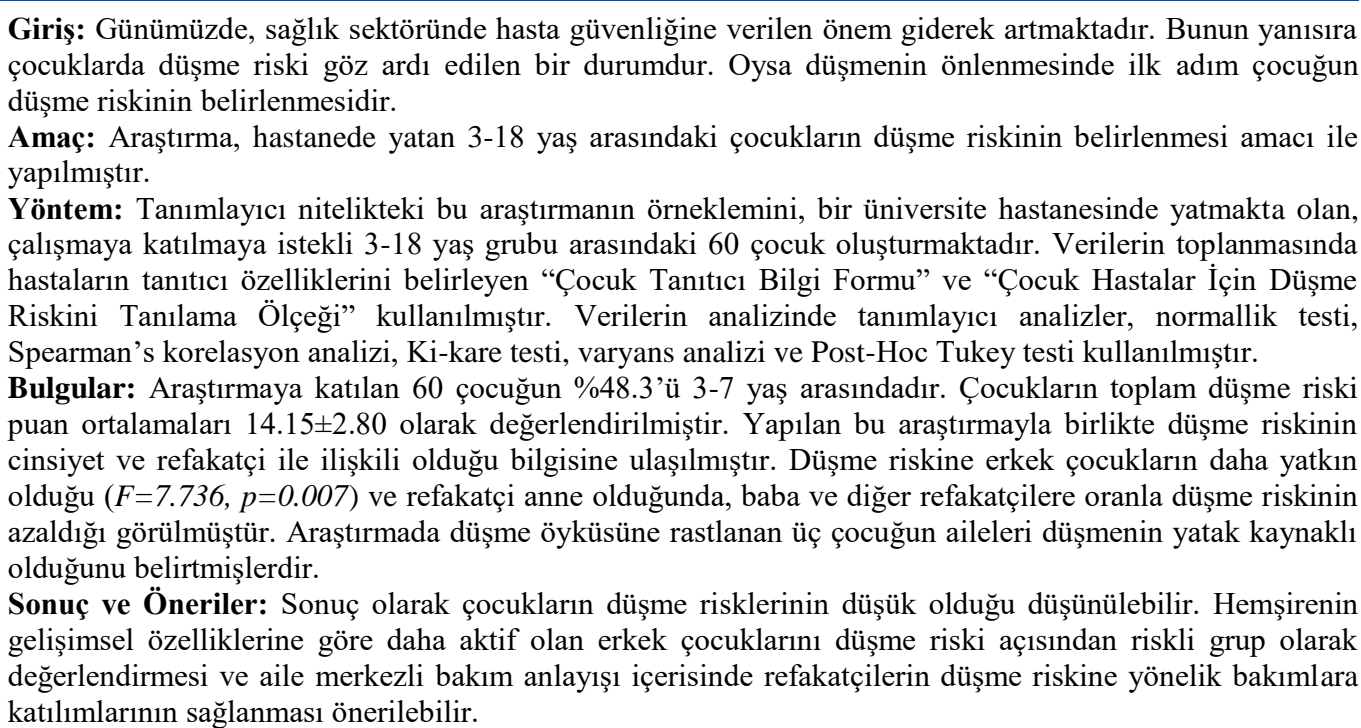 \\
\hline
\end{tabular}

\section{Determination of The Risk of Falling in Children Between 3-18 Years in}

\section{Hospital}

\begin{tabular}{|c|c|}
\hline Article Info & ABSTRACT \\
\hline $\begin{array}{l}\text { Keywords: } \\
\text { Falling risk, } \\
\text { Child, } \\
\text { Hospitalized child, } \\
\text { Pediatric nursing. }\end{array}$ & $\begin{array}{l}\text { Introduction: Today, the importance given to patient safety is increasing in the health sector. In addition, } \\
\text { the risk of falling in children is ignored. However, the first step in preventing a fall is to determine the } \\
\text { child's fall risk. } \\
\text { Objective: The research was conducted to determine the risk of falling in children between } 3-18 \text { years of } \\
\text { age in hospital. } \\
\text { Methods: The sample of this descriptive study consists of } 60 \text { children between the ages of } 3-18 \text { who are in } \\
\text { a University Hospital and willing to participate in the study. "Child Identification Data Sheet" and "Child } \\
\text { risk diagnostic scale for child patients" were used to determine the characteristics of the patient's } \\
\text { identification. Descriptive analyses, normality testing, Spearman's correlation analysis, Chi-square testing, } \\
\text { variance analysis, Post-Hoc Tukey testing were used in the analysis of the data. } \\
\text { Results: } 48.3 \% \text { of the } 60 \text { children who participated in the study are between } 3-7 \text { years old. The average } \\
\text { score of children at total risk of falling was } 14.15 \pm 2.80 \text {. The families of the three children who had a } \\
\text { history of falling in the study stated that the fall was caused by a bed. } \\
\text { Conclusions and Recommendations: As a result, children may be considered to have lower risk of falling. } \\
\text { It may be suggested that the nurse should evaluate the boys who are more active according to their } \\
\text { developmental characteristics as a risk group in terms of the risk of falling and that the chaperones should } \\
\text { participate in the care for the risk of falling within the family-centered care approach. }\end{array}$ \\
\hline
\end{tabular}

*Bu çalışma 27-30 Kasım 2019 tarihleri arasında İzmir'de düzenlenen 2. Uluslararası 7. Ulusal Pediatri Hemşireliği Kongresi'nde sözel bildiri olarak sunulmuştur.

Atıf/Citation: Çamurcu, K., Manav, G., \& Karayağız Muslu, G. (2020). Hastanede yatan 3-18 yaş arası çocukların düşme riskinin belirlenmesi, Genel Sağlık Bilimleri Dergisi, 2(3), 136-145. 


\section{GíRIŞ}

Günümüzde, sağlık sektöründe hasta güvenliğine verilen önem giderek artmaktadır (Demirel ve Demir, 2011, Yönt G.H., 2011). Hasta güvenliği, sağlık süreci boyunca hastaya önlenebilir bir zararın olmama durumudur ve sağlık hizmeti ile ilgili zarar riskinin kabul edilebilir düzeyde azaltılmasıdır. (World Patient Safety Day, 2019). Aynı zamanda sağlık hizmetinden kaynaklanan hataların azaltılması gerektiği, oluşan hataların hastada sebep olduğu hasarların engellenmesi veya azaltılmasıdır (Aslan ve Berke 2010). Tokyo Üçüncü Küresel Bakanlar Zirvesi'nde kabul edilen "Tokyo Hasta Güvenliği Deklarasyonuna” (2018) göre 2030 yılına kadar sağllk hizmetleri ile etkileşimleri surasında tüm hastalara ve insanlara zarar verme riskini ve önlenebilir zararları azaltmak için hasta güvenliğini arttırma konusunda taahhüt verilmiştir.

Dünya Sağl1k Örgütü (DSÖ)'ne göre kaliteli, güvenli hizmetin verilebilmesi için kurumlarda hasta güvenliği kültürünün gelişmesi gerekir. Kanıta dayalı uygulamaların yaygınlaşması ve sonuçlarının kullanılması için kurum içinde verilen eğitimlerin oranının arttırılması ve mesleki uygulamaların iyileştirilmesi, gözlenen hataların sebeplerinin araştırılması ve hatalarla ilgili süreçlerin belirlenmesi gereklidir (WHO,2011). Ciddi küresel halk sağlı̆g 1 sorunu olan hasta güvenliği tıbbi hataları; ilaç kullanımından kaynaklanan hatalar, cerrahi süreç hataları, yanlış konulan tanılar, sistem yetersizliği sonucu oluşan hatalar ve diğer alanlardaki hatalar olarak gruplandırmaktadır. Bu hatalara yönelik geliştirilen "Joint Commision International” 2010 hedefleri içerisinde "hastaların düşmelerine neden olan kaza ve yaralanmaları engel olma: risk belirlenmesi" yer almaktadır (Sayek,2010).

Düşme, kişinin dikkatsizlik, kaza gibi nedenlerle yerde ya da kendisinden daha alt bir düzeyde uzanır duruma gelmesi olarak tanımlanır (WHO, 2007). Pediatrik hastalar yaşanabilecek herhangi bir tıbbi hata karşısında savunmasızdır. Bu nedenle pediatri klinikleri hasta güvenliği uygulamaları konusunda daha fazla çaba harcanması gerektiren birimlerdir (Başbakkal, Bayılmaz ve Taş, 2009).

Çocuklar, gelişimsel nitelikleri bakımından düşmelerle karşılaşmada risk düzeyi yüksek gruplar olarak tanımlanmaktadır. Bu konunun sebebi ise nöromotor, fiziksel, duyusal, bilişsel ve psikososyal açıdan gelişim düzeylerinin gelişmeye devam etmekte olmasıdır. Motor sistemlerinin tam gelişmemesi, denge sağlamada zorluk yaşamaları, seslerin yerlerini algılama yeteneklerinin henüz gelişmemiş olması, birden fazla uyarıyı aynı anda algılayamıyor olması, sürekli hareket halinde olmaları, araştırma ve öğrenmeye yönelik konularda oluşan merakları çocukların çeşitli kazalarla karşılaşmalarına sebebiyet vermektedir (Efe ve Pazarcıkcı, 2018).

Chroma (2016), çocuk kliniklerinde düşme riskini ölçen güvenilir bir ölçme aracı kullanılmasını ve risk alanlarının belirlenmesini önermektedir. Ayrıca, düşme riskinin belirli aralıklarla analizinin yapılmasını, riskli hastalar için düşme sembolü ve çıkartmalarının kullanılmasını, düşme riski olan hastaya kol bandı takılmasını, pediatri kliniğinde özel hasta yataklarının kullanılmasını ve hasta transferinden kaynaklanan düşmelerin önlenmesine yönelik sağlık bakım profesyonellerine eğitim verilmesini tavsiye etmektedir (Chroma, 2016). Ülkemizde Harizmi Düşme Riski Ölçeği ve dört yapraklı yonca düşme sembolü Sağlık Bakanlığına bağlı kurumlarda kalite standartları gereği hasta güvenliği uygulamaları kapsamında kullanılmaktadır (T.C. Sağlık Bakanlığ 1,2017$)$.

Kliniklerde hasta güvenliğinin sağlanması hemşirenin ana sorumluluklarından biridir. Düşmeyi riskini engellemeye yönelik hemşirelik uygulamaları ile birlikte düşmelerin en aza indirilebilmesi açısından önem taşımaktadır. Düşmelerin engellenmesinde hemşirelerin düşme riskini değerlendirmesi, çevresel düzenlemeler, birey ve bakımından sorumlu olan kişilere eğitim verilmesi gibi sorumlulukları vardır. (Fertelli, Mollaoğlu ve Özkan, 2013). Düşmeyi önlenmek için yapılması gereken ilk adım hastanın düşme riskinin belirlemektir. Riskin belirlenmesi için bireyi doğru ve yeterli değerlendirilmesi gerekmektedir. Yapılan değerlendirmelerde bütüncül bir yaklaşım kullanılmalıdır. Hemşire düşme riskini belirleme araçlarını doğru kullanarak hasta bireyin düşme riskini önceden belirleyebilir ve düşmenin önlenmesine yönelik yapacağ 1 hemşirelik girişimlerini de bu doğrultuda planlayabilir (Oksel, 2018). 


\section{Amaç}

Çocukların düşme açısından risklerinin yüksek olduğu göz önünde tutularak pediatri hemşirelerinin kliniklerde uygulamaları içerisine düşme riskini değerlendirmeyi eklemelidir. $\mathrm{Bu}$ nedenle bu araştırmada çocukların düşme risklerinin belirlenmesi amaçlanmıştır.

\section{YÖNTEM}

\section{Araştırmanın Tipi}

Bu araştırma 3-18 yaş çocuklarda düşme riskini belirlemek amacıyla tanımlayıcı olarak yapılmıştır.

\section{Araştırmanın Evreni ve Örneklemi}

Araştırmanın evrenini 2019 yılında Haziran - Eylül ayları arasında pediatri ve pediatrik cerrahi servislerinde yatarak tedavi gören 3-18 yaş çocuklar oluşturmuştur. Araştırmanın örneklemini ise araştırmanın başlatıldığ tarihten itibaren adı geçen servislerde tedavi gören ve araştırmaya dahil edilme kriterlerini kapsayan, çalışmaya katılmayı kabul eden ailelerin çocukları olan 3-18 yaş grubu arasındaki 60 çocuk oluşturmaktadır.

\section{Veri Toplama Araçları}

Araştırmada veriler "Çocuk Tanıtıcı Bilgi Formu” ve "Çocuk Hastalar İçin Düşme Riskini Tanılama Ölçeği” kullanılarak, çocuk hasta odalarında toplanmıştır. Çocuk tanıtıcı bilgi formu ebeveynlerle yüz yüze görüşülerek araştırmacı tarafindan doldurulmuştur. "Çocuk Hastalar İçin Düşme Riskini Tanılama Ölçeği” ise doldurulurken gözlem yöntemi kullanılmıştır. Tarafsız bir çalışma olması amacıyla araştırmacı dışında bir servis hemşiresinden yardım alınarak toplam iki kişi görev almıştır. Verilerin toplanması her katılımcı için yaklaşık 2030 dakika sürmüştür.

Çocuk Tanttıcı Bilgi Formu; Araştırmacı tarafından literatür doğrultusunda (Jamerson ve ark., 2014, Schafferetal, 2012) oluşturulan form çocuğun yaşı, cinsiyeti, yattığı klinik, tanısı, düşme öyküsü, refakatçisi, annenin eğitim düzeyi, aile tipi, algılanan gelir düzeyi, kardeş sayısı gibi tanıtıcı özelliklerini belirleyen 10 sorudan oluşmaktadır.

Çocuk Hastalar İçin Düşme Riski Tanılama Ölçeği; Demir ve arkadaşları (2013) tarafindan geliştirilen ölçek 11 alandan oluşmuştur (Demir, Çevik Yöntem, Yıldırım Sarı ve Bektaş, 2013). Alanlarda yer alan her bir madde sorun düzeyine göre ayrılmıştır. Düşme riski olarak belirlenen 11 alan; çocuğun yatışı yapılan klinik, çocuğun yaşı, düşme öyküsü, tanısı, mental durumu, yaşam bulguları, tedavisi, sedasyon alma durumu, mobilizasyonda kısıtlılık durumu, bakım veren kişi, klinik uygulamalar ve çevresel faktörlerden oluşmaktadır. Ölçek maddelerinden alınan toplam puan ile risk puanı (kesim noktasına göre) 16.5 puan ve üstü bulunmakla birlikte; uygulamada buçuklu puan kullanımının zorluğu nedeniyle, klinik kullanımda 17 ve üstünün riskli olarak ele alınması önerilmiştir. Araştırmamızda \%95 güven aralığında ölçeğin cronbach alpha değeri .65 (.37- .46) olarak değerlendirilmiştir.

\section{Veri Toplama}

Araştırma Muğla il merkezinde bulunan bir eğitim ve araştırma hastanesinin pediatri, pediatrik cerrahi servislerinde yürütülmüştür. Tanımlayıcı nitelikteki bu araştırma Haziran- Eylül 2019 tarihleri arasında yapılmıştır.

\section{Verilerin Analizi}

Veriler bilgisayar ortamında SPSS programı kullanılarak değerlendirilmiştir. Verilerin analizinde tanımlayıcı analizler, normallik testleri, Post-Hoc Tukey testi, Spearmans korelasyon analizi ve ki kare testi kullanılmıştır. 


\section{Etik}

Araştırmanın uygulanabilmesi için; Muğla İl Sağlık Müdürlüğü’nden kurum izni (27.03.2019 Tarih ve 33868 Say1), Muğla Sitkı Koçman Üniversitesi Girişimsel Olmayan Etik Kurul İzni 20.05.2019 Tarih ve 93 sayı) ve çalışmaya katılan çocukların ebeveynlerin gönüllü olurları alınmıştır.

\section{BULGULAR}

Araştırmaya katılan 60 çocuğun \%48.3'ü 3-7 yaş arasındadır. Araştırmaya katılan çocukların \%51.7'si erkek, \%48.3'ü kızdır. Araştırmanın yapıldığı dönemde çocuklar en fazla \%26,7 solunum sistemi hastalıklarından dolayı hastanede yatmaktadır (\%26.7) ve 49 çocuğa (\%81.7) hastanede yattığı süre içerisinde annesi refakat etmektedir. Anneye ait bazı sosyodemografik verilere bakıldığında 41'inin (\%68.3) lise mezunu, 55 'inin çekirdek aile olduğu (\%91.7), gelir düzeylerinin 28 annenin gelirinin giderine eşit olduğu (\%46.7) görülmüştür. Hastanede yatan çocukların 26'sının (\%43.4) bir kardeşi olduğu görülmüştür. Araştırmaya katılan 60 çocuktan \%5'inin ailesi çocuğunun düştüğünü ifade etmiştir. Çocuk ve ailesine ait tanıtıcı özellikleri Tablo 1'de verilmiştir.

Tablo 1. Çocuk ve Ailesine Ait Tanitıcı Özellikler $(n=60)$

\begin{tabular}{|c|c|c|c|}
\hline Özellikler & & Sayı & Yüzde (\%) \\
\hline \multirow[t]{3}{*}{ Çocuk yaşı } & 3-7 yaş & 29 & 48.3 \\
\hline & $8-12$ yaş & 17 & 28.3 \\
\hline & $13-17$ yaş & 14 & 23.3 \\
\hline \multirow[t]{2}{*}{ Cinsiyet } & $\mathrm{K}_{1 \mathrm{Z}}$ & 29 & 48.3 \\
\hline & Erkek & 31 & 51.6 \\
\hline \multirow[t]{2}{*}{ Yattığı Klinik } & Çocuk cerrahi & 28 & 46.6 \\
\hline & Çocuk servisi & 32 & 53.3 \\
\hline \multirow[t]{7}{*}{ Tanısı } & Solunum sistemi has. & 16 & 26.6 \\
\hline & Boşaltım sistemi has. & 7 & 11.6 \\
\hline & Sinir sistemi has. & 11 & 18.3 \\
\hline & GİS has. & 10 & 16.6 \\
\hline & Dolaşım sistemi has. & 2 & 3.33 \\
\hline & Endokrin sistemi has. & 9 & 15 \\
\hline & Diğer hastalıklar & 5 & 8.33 \\
\hline \multirow[t]{4}{*}{ Refakatçisi } & Anne & 49 & 81.6 \\
\hline & Baba & 3 & 5 \\
\hline & Anne-baba & 6 & 10 \\
\hline & Diğer & 2 & 3.33 \\
\hline \multirow{2}{*}{ Düşme öyküsü } & Var & 3 & 5 \\
\hline & Yok & 57 & 95 \\
\hline \multirow[t]{3}{*}{ Anne eğitim } & İlköğretim & 6 & 10 \\
\hline & Lise & 41 & 68.3 \\
\hline & Lisans & 13 & 21.6 \\
\hline \multirow[t]{2}{*}{ Aile tipi } & Çekirdek & 55 & 91.6 \\
\hline & Geniş & 5 & 8.33 \\
\hline \multirow[t]{3}{*}{ Gelir düzeyi } & Gelirim giderimden az & 9 & 15 \\
\hline & Gelirim giderime eşit & 28 & 46.6 \\
\hline & Gelirim giderimden fazla & 23 & 38.3 \\
\hline
\end{tabular}

Çocuk Hastalar İçin Düşme Riski Tanılama Ölçeği'nin toplam ve alt gruplarına göre ortalama puanları Tablo 2'de verilmektedir. Çalışmaya katılan çocukların toplam düşme riski puan ortalamaları $14.15 \pm 2.80$ olarak değerlendirilmiştir. 
Tablo 2. Çocuk Hastalar İçin Düşme Riski Tanılama Ölçeğinin Toplam ve Alt Gruplarına Göre Ortalama Puanlarl

\begin{tabular}{llll}
\hline Özellikler & Min & Max & Ortalama \pm SS \\
\hline Klinikler & 1 & 3 & $1.73 \pm 0.97$ \\
Yaş & 1 & 4 & $2.25 \pm 1.05$ \\
Düssme & 1 & 2 & $1.06 \pm 0.25$ \\
Tanı & 1 & 5 & $1.58 \pm 1.40$ \\
Mental durum & 1 & 2 & $1.05 \pm 0.21$ \\
Yaşam bulguları & 1 & 2 & $1.03 \pm 0.18$ \\
Tedavi & 1 & 3 & $1.16 \pm 0.55$ \\
Sedasyon alma & 1 & 1 & $1.00 \pm 0.00$ \\
Mobilizasyonda kısıtlama & 1 & 2 & $1.08 \pm 0.27$ \\
Bakım veren kişi & 1 & 2 & $1.13 \pm 0.34$ \\
Çevresel faktörler & 1 & 21 & $1.05 \pm 0.21$ \\
Toplam düşme & 11 & & $14.1 \pm 2.80$ \\
\hline
\end{tabular}

Tablo 3'te Çocuk Hastalar İçin Düşme Riski Tanılama Ölçeği kullanılarak ulaşılan verilerin düşme riski değerlendirilmiştir. Tabloya bakıldığında yaş ortalamasının diğer verilerden daha yüksek olduğu ve yaşın düşme üzerinde etkisinin diğer verilere göre daha etkili olduğu sonucuna ulaşılmıştır.

Tablo 3. Klinikte Yatan Çocukların Düşme Riski Durumu ile Düşme Durumlarının Karşıllaştırılması

\begin{tabular}{|c|c|c|c|c|c|c|}
\hline \multirow[t]{2}{*}{ Özellikler } & \multicolumn{2}{|c|}{ Düşük } & \multicolumn{2}{|c|}{ Yüksek } & \multirow{2}{*}{$\begin{array}{l}\text { İstatistiksel } \\
\text { değerlendirme }\end{array}$} & \multirow[t]{2}{*}{$\mathbf{p}$} \\
\hline & $\mathbf{N}$ & $\%$ & $\mathrm{n}$ & $\%$ & & \\
\hline \multicolumn{7}{|l|}{ Yaş } \\
\hline $3-7$ yaş & 22 & 44 & 7 & 70 & $\chi^{2}=2.646$ & .266 \\
\hline $8-12$ yaş & 16 & 32 & 1 & 10 & & \\
\hline $13-17$ yaş & 12 & 24 & 2 & 20 & & \\
\hline \multicolumn{7}{|l|}{ Cinsiyet } \\
\hline $\mathrm{K}_{1 \mathrm{z}}$ & 28 & 56 & 1 & 10 & $\mathrm{~F}=7.736$ & .007 \\
\hline Erkek & 22 & 44 & 9 & 90 & & \\
\hline Yattığı Klinik & & & & & $\chi^{2}=3.858$ & \\
\hline Çocuk servisi & 23 & 46 & 8 & 80 & & .051 \\
\hline Çocuk cerrahi & 27 & 54 & 2 & 20 & & \\
\hline \multicolumn{7}{|l|}{ Refakatçisi } \\
\hline Anne & 43 & 86 & 6 & 60 & $\chi^{2}=12.490$ & .006 \\
\hline Baba & 2 & 4 & 4 & 40 & & $1>2.3 .4^{*}$ \\
\hline Anne-baba & 3 & 6 & 0 & 0 & & \\
\hline Diğer & 2 & 4 & 0 & 0 & & \\
\hline \multicolumn{7}{|l|}{ Tanısı } \\
\hline Solunum sis. & 13 & 26 & 3 & 30 & & \\
\hline Boşaltım sis. & 5 & 10 & 2 & 20 & $\chi^{2}=4.542$ & .604 \\
\hline Sinir sis. & 9 & 18 & 2 & 20 & & \\
\hline Gis & 9 & 18 & 1 & 10 & & \\
\hline Dolaşım sis. & 1 & 2 & 1 & 10 & & \\
\hline Endokrin sis. & 4 & 8 & 1 & 10 & & \\
\hline Diğer sis. & 9 & 18 & 0 & 0 & & \\
\hline \multicolumn{7}{|l|}{ Düșme öyküsü } \\
\hline Var & 3 & 6 & 0 & 0 & & .573 \\
\hline Yok & 47 & 94 & 10 & 100 & $\chi^{2}=0.632$ & \\
\hline \multicolumn{7}{|l|}{ Anne eğitim } \\
\hline İlköğretim & 5 & 10 & 1 & 10 & & \\
\hline Lise & 34 & 68 & 7 & 70 & $\chi^{2}=1.220$ & .748 \\
\hline Lisans & 11 & 22 & 2 & 20 & & \\
\hline \multicolumn{7}{|l|}{ Aile tipi } \\
\hline Çekirdek & 46 & 92 & 9 & 90 & $\chi^{2}=5.173$ & .075 \\
\hline Geniş & 4 & 8 & 1 & 10 & & \\
\hline \multicolumn{7}{|l|}{ Gelir düzeyi } \\
\hline Gelir giderden az & 8 & 16 & 1 & 10 & $\chi^{2}=2.652$ & .266 \\
\hline Gelir gidere eşit & 21 & 42 & 7 & 70 & & \\
\hline Gelir gidere fazla & 21 & 42 & 2 & 20 & & \\
\hline
\end{tabular}




\begin{tabular}{lcccccc}
\hline Kardeş sayısı & & & & & \\
$0-2$ & 23 & 82 & 9 & 90 & $\chi^{2}=3.536$ & \\
2 yaş üstü & 9 & 18 & 1 & 10 & & \\
& & & 0 & 0 & & \\
& & & 0 & 0 & & \\
\hline
\end{tabular}

*Post-Hoc Tukey analizine göre belirlenmiştir.

Düşme riskini etkileyen faktörler ölçeğinin alanlarının birbiriyle ilişkileri Tablo 4'de verilmektedir. Düşme riski etkileyen faktörler ile düşme aralarında ilişki istatistiksel olarak anlamlı değerlendirilmemiştir.

Tablo 4. Düşme Riskini Etkileyen Faktörlerin Düşme Riski İle İlişkisinin Değerlendirilmesi

\begin{tabular}{lcc}
\hline Çocuk Hastalar İçin Düşme Riski Tanılama Ölçeği Alanları & \multicolumn{2}{c}{ Düşme riski puanı } \\
\cline { 2 - 3 } Klinikler & Spearman's Correlation & (r) \\
\hline Yaş & .074 & .574 \\
\hline Düşme Öyküsü & -.163 & .213 \\
\hline Tanısı & 1 & - \\
\hline Mental Durum & -.112 & .394 \\
\hline Yaşam Bulguları & -.061 & .642 \\
\hline Tedavi & -.050 & .706 \\
\hline Sedasyon Alma & -.081 & .541 \\
\hline Mobilizasyonda Kısıtlama & - & - \\
\hline Bakım Veren Kişi & -.081 & .541 \\
\hline Çevresel Faktörler (yatak kenarları, cam kenarları v.s) & -.105 & .425 \\
\hline
\end{tabular}

\section{TARTIŞMA}

Düşme çocukluk döneminde önemli bir sorundur (Harris, Rochette ve Smith, 2011). Hastanede yatan 3-18 yaş arası çocuklarda düşme riskinin belirlenmesi amacıyla yapılan bu araştırmada çocuk hastalar için düşme riski tanılama ölçeği puan ortalaması $14.1 \pm 2.80$ olarak bulunmuştur (Tablo 2). Ölçeğe göre 16,5 ve üstü düşme riskinin fazla olduğu anlamına gelmektedir (Demir, Çevik Yöntem, Yıldırım Sarı ve Bektaş, 2013). Fakat yapılan bu araştırmada puan ortalaması düşme riski ortalamasının altında kalmıştır. Bunu göz önünde bulundurarak çocukların düşme risklerinin düşük olduğu düşünülebilir.

Düşme riskini etkileyen faktörler arasında çocuğun cinsiyeti ve rekatçinin anne olmasının olduğu görülmüştür. Çocuk hastaların düşme riskini belirlemek amacıyla yapılan bu araştırma katılan 60 çocukta düşmenin \%70 oranında 3-7 yaş grubundaki çocuklarda gerçekleştiği ve düşen çocukların \%90 oranının erkek çocuklarda gerçekleştiği saptanmıştır. Harris ve arkadaşlarının (Harris, Rochette ve Smith, 2011) Amerika'da yaptığı çalışmada düşme kaynaklı acil servise gelen 98.145 hastadan her yıl yaklaşık olarak 5180 çocukta düşme durumu görüldüğü, düşen çocukların da yaş ortalamalarının da 5.1 olduğu ve erkek çocuklarda kız çocuklara oranla düşmenin daha fazla gerçekleşmekte olduğu saptanmıştır. Yapılan diğer çalışmalara bakıldığında (Cooper \& Nolt, 2007; Graf,2011; Harvey ve ark., 2010; Neiman ve ark., 2011; Razmus ve ark., 2006) erkeklerin kızlardan daha çok düştüğüne rastlanılmıştır. Yapılan bu araştırma da düşen erkek sayısının kız sayısından fazla olduğuna rastlanılmış ve düşme riski puan ortalamasında erkeklerin \%90 daha riskli grup olduğu kanısına varılmıştır. Verilerin literatür ile uyumlu olduğu ve düşme riskinin erkek çocuklarda yüksek olmasının büyüme gelişme özelliklerine göre kız çocuklarına oranla daha hareketli olmalarından kaynaklı olduğu söylenebilir.

Çocuğa bakım vermekle sorumlu bireyler çoğunlukla hastanede çocuklarına eşlik eden ve onların bakımında rol oynayan kişilerdir. Görülen bu durumlar aileleri sürekli etkilemektedir. Ebeveynlerin veya onların bakımından görev alan bireylerin hastanedeki ihtiyaçları son zamanlarda sağlık literatüründe dikkat çeken konular arasında bulunmaktadır (Shields et al. 2003). Bialoskurski ve arkadaşları (2002), annelerin sağlık 
personeli ile iyi bir iletişim kurmanın gerekliliğini ve annelerin fedakârlık yaparak kendi ihtiyaçlarını ikinci plana bırakarak önceliklerinin çocuklar üzerinde olduğunu belirlemişlerdir. Araştırmada düşme riski ile refakatçi arasında bağlantı olduğu bilgisine ulaşılmıştır. Yanında refakatçi olarak anneleri bulunan çocuklarda düşme riskinin daha az olduğu saptanmıştır. Primer bakım verici annelerin çocuklarıyla daha yoğun bir iletişim kumalarından dolayı düşme riski puanına etki ettikleri düşünülmüştür.

Düşme riskinin en sık görüldüğü hastalıklar; Jamerson ve arkadaşlarının (2014) yaptığı çalışmada 'diğer tanılar', Hill- Rodruguez ve arkadaşlarının (2009) yaptığ 1 çalışmada nörolojik hastalıklar grubunda görüldüğü bildirilmiştir. Jamerson ve arkadaşlarının (Jamerson ve ark., 2014) çalışmasında düşmenin en sık görüldüğü tanıları 'diğer tanılar' olarak bulmuştur. Hill- Rodruguez ve ark. (Hill-Rodruguez ve ark., 2009) yaptığı çalışmada ise düşmenin en çok rastlanan tanıların nörolojik hastalık kaynaklı olduğuna rastlamışlardır. Araştırmada ise düşme riski en sık solunum sistemi rahatsızlıklarında görülmüştür.

Eğitim seviyesinin artmasıyla birlikte refakatçilerin de sorunlarla baş edebilmeleri, doğuştan gelen olunan problem çözmeye yönelik yeteneklerinin eğitim etkisi olduğunu göstermektedir (Taylan, 1997). Bu çalışmada ise anne eğitim düzeyine bakıldığında düşme riski en yüksek \%70 olarak annenin eğitiminin lise mezunu olduğu görülmüştür. Düşme riskinin anne eğitimiyle ilişkisi olmadığı istatistiksel olarak saptanmış olsa da en düşük düşme riski puanının ilkokul mezunu annelerde olduğu saptanmıştır.

Pediatrik hastalar, büyüme ve gelişme evreleri nedeniyle ek düşme riski taşırlar. İlaç kullanımı, yeni bir ortam ve altta yatan tıbbi durumlar, çocukların yönelimini ve anlaşılmasını engelleyebilir ve bu da düşme riskini artırabilir (Cooper, 2007). Anneleri kendi yaşam alanlarında kullandıkları yataklar dışında hastanede kullandıkları yatakları tanımamaları ve alışkın olmadıkları çevre nedeniyle tedirginlik yaşamalarından bu yatakları kullanma zorluğu yaşadıkları düşünülmüştür. Yapılan bu çalışmada ise Tablo 4 e baktığımız zaman değişkenlerin düşme riski üzerine anlamlı bir etkisi olmadığına ulaşılmıştır.

Jamerson ve arkadaşlarının (Jamerson ve ark., 2014) çalışmasında düşme riski, oryante, yaşı gelişimsel dönemine uygun, aktif, denge faktörü yeterli olan çocuklarda daha yüksek, sedasyon sağlayan ve anestetik madde kullanımının düşme riski ile ilişkili olmadığını saptamıştır. Yapılan bu araştırmada da literatür ile uyumlu olarak düşme riskinin çoklu ilaç kullanımı, sedasyon alma, tedavi ve oryantasyonun bozuk veya oryante olması, yaş aralığ1 ve mobilizasyonda kısıtlama olmasıyla ilişkili olmadığına ulaşılmıştır.

\section{SONUÇ ve ÖNERÍLER}

Araştırma hastanede yatan 3-18 yaş arası çocuklarda düşme riskini ve etkileyen faktörlerin belirlenmesi ve belirlenen faktörlerin engellenebilmesi bakımından önem taşımaktadır. Bu araştırmadan ulaşılacak verilerin çocuk servislerinde düşme riskini azaltmak amacıyla yapılacak eğitim programlarının içeriklerinin ve önceliklerinin belirlenmesinde yardımcı olacağı düşünülmüştür.

Yapılan bu araştırmada, çocuğun yaşının, yattı̆̆ kliniğin, kardeş sayısının, gelir düzeyinin, aile yapısının düşme üzerinde bir etkisi olmadığına ulaşılmıştır. Bu araştırmayla Düşme riskini etkileyen faktörlerin çocuğun cinsiyetine ve refakatçisine bağlı olduğu saptanmıştır. Bununla beraber annenin; baba veya diğer refakatçilere oranla düşme riski üzerine olumlu etkileri olduğuna ulaşılmıştır. Düşme öyküsüne rastlanan üç çocuğun aileleri düşmenin yatak kaynaklı olduğunu ve genellikle kullanışsız olduğunu ifade etmiştir. Düşme öyküsü olan üç çocuğun da erkek olduğu ve yanlarında anne dışında bir refakatçi kaldığı öğrenilmiştir.

Hastanede düşme risklerini en aza indirebilmek amacıyla, hastaların refakatçisi olarak yanlarında annelerin kalması önerilebilir. Bunun yanı sıra hastaların refakatçilerine düşme riskini önlemeye yönelik ve hasta yataklarının nasıl kullanılacağına dair bilgilendirme yapılabilmesi önerilmektedir. Bununla birlikte hastanede yatan çocuklara yönelik, pediatri uzmanları tarafından riskli hareketlerin yol açabileceği kazaları, yatakta oyun oynarken nelere dikkat edilmesi gerektiği konusunu çocukların anlayabileceği yaş gruplarına göre anlatılabilir.

\section{Finansal destek}

Çalışmada herhangi bir finansal destek alınmamıştır. 


\section{Çıkar çatışması}

Çalışmada bir çıkar çatışması yoktur.

\section{Yazarlık Katkıları:}

Tasarım/Design: K.Ç.; Veri Toplama ve Veri Girişi Yapma/Data Collection or Processing: K.Ç., G.M.,

G.K.M.; Analiz ve Yorum/Analysis or Interpretation: K.Ç., G.M.; Literatür Tarama/Literature Search: K.Ç., G.M.; Yazma/Writing: K.Ç.

\section{KAYNAKÇA}

Başbakkal, Z., Taş, F., Balyılmaz, H. (2009). Pediatri kliniklerinde çalışan hemşirelerin hasta güvenliği kültürüne ilişkin görüşlerinin incelenmesi. Ege Pediatri Bülteni,16(2): 71-122.

Berke, D., Aslan F.E. (2010). Cerrahi hastalarını bekleyen bir risk: Düşmeler, nedenleri ve önlemler. Anadolu Hemşirelik ve Sağlık Bilimleri Dergisi, 13(4):72-77.

Bialoskurski M.M., \& Cox C.L., Wiggins R.D. (2002). The relationship between maternal needs and priorities in a neonatal intensive care environment. Journal of Advanced Nursing January, 37(1):62-69.

Chroma J. (2016). Risk of falling in Pediatrics nursing. Central Europen Journal of Nursing and Midwifery, 7(4): 542-548.

Cooper, C.L., \& Nolt, J.D. (2007). Develop ment of an evidence-based pediatric fall prevention program. Journal of Nursing Care Quality, 22 (2), 107-112. doi: 10.1097/01.NCQ.0000263098.83439.8c.

Demir, D., Çevik Yöntem, S., Yıldırım Sarı, H., Bektaş, M. (2013). Çocuklar için düşme riski tanılama ölçeğinin geliştirilmesi, , 10 (3) s: 34-41

Derin, N., Demirel, E. (2011 Hemşirelikte Eğitim ve Araştırma Dergisi). Hastanelerde verimlilik artışı için hasta güvenliği uygulamaları ve hasta güvenliğinin sağlanmasında dönüşümcü liderliğin etkisi. Verimlilik Dergisi, (3): 51-81

Füsun Sayek Türk Tabipleri Birliği raporları/kitapları (2010), Hasta Güvenliği ve Dünya, s.17-18

Graf, E. (2011). Magnet children's hospitals: Leading knowledge development and quality standards for inpatient pediatric fall prevention programs. Journal of Pediatric Nursing, 26, 122-127.doi: 10.1016/j.pedn.2010.12.007

Yönt, G.H. (2011). Hasta güvenliği kültürü. Ege Üniversitesi Hemşirelik Yüksek Okulu Dergisi, 27 (1): 77-82.

Harris, V.A., Rochette, L.M. \& Smith, G.A. (2011). Pediatric injuries attributable to falls from windows in the United States in 1990- 2008. Pediatrics, 128(3):455-462. https://doi.org/10.1542/peds.2010-2687

Harvey, K., Kramlich, D., Chapman, J., Parker, J., \& Blades, E. (2010). Explor ing and evaluating five paediatric falls assessment instruments and injury risk indicators: An ambispective study in a tertiary care setting, Journal of Nursing Management, 18, 531-541. doi: 10.1111/j.1365-2834.2010.01095.x.

Jamerson, P.A., Graf, E., Messmer, P.R., Fields, H.W., Barton, S., Berger, A., et al. (2014). Inpatient falls in freestanding children's hospitals. Pediatric Nursing, 40(3):127-135.

Mollaoğlu, M., Fertelli, T. ve Tuncay, F. (2013). Dahili kliniklerde yatan bireylerin düşme riski ve alınan önlemlerin incelenmesi, TAF Preventive Medicine Bulletin, 12(1),27-34.

Neiman, J., Rannie, M., Thrasher, J., Terry K. \& Kahn, M.G. (2011). Development, implementation, and evaluation of a comprehensive fall risk program. Journal for Specialists in Pediatric Nursing, 16 (2), 130-139. doi: 10.1111/j.17446155.2011.00277.x.

Oksel, E. (2018). Düşmeye Hemşire Bakışı ve Değerlendirilmesi, Aegean Journal Medical Science, 4:140-142.

Pazarcıkcı, F. ve Efe, E. (2018). Pediatri hemşireliğinde hasta güvenliği, SDÜ Sağlık Bilimleri Enstitüsü Dergisi, 9(2): 169174.

Razmus, I., Wilson, D., Smith, R. \& Newman, E. (2006). Falls in hospitalized children. Pediatric Nursing, 32, 568-572.

Schaffer, P.L., Daraiseh, N.M., Lynn, D., Ed, M., Li, L., Myra, M.H, et al. (2012). Pediatric inpatient falls and injuries: A descriptive analysis of risk factors. Pediatric Nursing, 17; 10-18. doi: 10.1111/j.1744-6155.2011.00315.x. Epub 2011 Nov 10.PMID: 22188268

Shields, L., Kristensson-Hallström, I., O'Callaghan, M. (2003). An examination of the needs of parents of the hospitalized children: comparing parents' and staff's perceptions. Nordic College of Caring Sciences, Scandinavian Journal of Caring Science, 176-184.

Taylan, S. (1997). Heppner'in problem çözme envanterinin uyarlama, güvenirlik ve geçerlik çalışmaları. Yüksek Lisans Tezi. Ankara Üniversitesi Sosyal Bilimler Enstitüsü, Ankara.

Third Global Ministerial Sumbit On Patient Safety (2018), Tokyo Decleration on Patient Safety. Tokyo, Japan.

Türkiye Cumhuriyeti Sağlık Bakanlığı (2017). Erişim Tarihi: 13.03.2019 https://kalite.saglik.gov.tr/TR,13485/harizmidusme-riski-olcegi.html 
WHO, Global Report on Falls Prevention in Older Age (2007). Date of Electronic Publication:13.03.2019 https://www.who.int/violence_injury_prevention/publications/other_injury/falls_prevention.pdf?ua=1

WHO, Patient Safety Curriculum Guide (2011). Date of Electronic Publication:13.03.2019 https:/www.who.int/patientsafety/education/mp_curriculum_guide/en/

WHO, World Patient Safety Day (September, 2019). Date of Electronic Publication:14.03.2019 https://www.who.int/patientsafety/en/ 


\section{EXTENDED ABSTRACT}

Introduction: Today, the importance given to patient safety is increasing in the health sector. In addition, the risk of falling in children is ignored. However, the first step in preventing a fall is to determine the child's fall risk.

Objective: The research was conducted to determine the risk of falling in children between 3-18 years of age in hospital.

Methods: The sample of this descriptive study consists of 60 children between the ages of 3-18 who are in a University Hospital and willing to participate in the study. "Child Identification Data Sheet" and "Child risk diagnostic scale for child patients" were used to determine the characteristics of the patient's identification. A total of two people were employed with the assistance of an impartial working password researcher and a ward nurse. Data collection may take approximately 20-30 minutes for its participant. Descriptive analyses, normality testing, Spearman's correlation analysis, Chi-square testing, variance analysis, and Post-Hoc Tukey testing were used in the analysis of the data. Fall Risk Diagnostic Scale for Pediatric Patients: 11 areas with risk of falling; It consists of clinical applications and clinical applications consisting of clinical applications, reasoning status, life findings, treatment, sedation status, limitation in mobilization, clinical applications and questions.

Results: $48.3 \%$ of the 60 children who participated in the study are between 3-7 years old. The average score of children at total risk of falling was $14.15 \pm 2.80$. With this research, it was found that the risk of Falls was related to gender and companion. It was found that boys were more prone to fall risk $(\mathrm{F}=7.736, \mathrm{p}=0.007)$ and that when the companion was a mother, the risk of falling was reduced compared to the father and other companions. The families of the three children who had a history of falling in the study stated that the fall was caused by a bed.

Discussion: In this study, the average score was below the falling risk average. With this in mind, it can be thought that the risk of falling children is low. The gender of the child and the mother being the recipient were observed to be among the factors affecting the risk of falling. In this study, which was conducted to determine the risk of falling in pediatric patients, it was found that $70 \%$ of the falls occurred in children between the ages of 3-7 and $90 \%$ of the falling children occurred in boys. In the study, it was found out that there was a connection between the risk of falling and the companion. It was found that the risk of falling was lower in children who had mothers as their companions. It was thought that the primary caregiver mothers had a more intense communication with their children, which contributed to the falling risk score. In this study, in accordance with the literature, it was found that the risk of falling was published with the use of multiple drugs, sedation, disorientation in treatment and orientation, age range and limitation in mobilization. When we look at the education level of the mother, it was seen that the mother's education was high school graduate with the highest risk of falling with $70 \%$. Although it was statistically determined that falling risk was not related to mother education, the lowest fall risk score was found to be in mothers who graduated from primary school.

Conclusions and Recommendations: In the research, falling and interaction of factors are of great importance in hospitalized children aged 3-18. As a result, children may be considered to have lower risk of falling. It may be suggested that the nurse should evaluate the boys who are more active according to their developmental characteristics as a risk group in terms of the risk of falling and that the chaperones should participate in the care for the risk of falling within the familycentered care approach. In order to minimize the risk of falling in the hospital, it may be recommended that mothers stay with them as the patient's companion. In addition, it is recommended that the attendants of the patients be informed about the risk of falling and how to use the patient beds. On the other hand, pediatricians can explain the accidents that may be caused by risky movements and what should be paid attention when playing in bed for children hospitalized according to age groups that children can understand. It is thought that the data obtained from this research will help determine the contents and priorities of the education programs to be carried out in order to reduce the risk of falling in children's services. 